\title{
Pharmacogenetics and Age-Related Macular Degeneration
}

\author{
Stephen G. Schwartz ${ }^{1}$ and Milam A. Brantley Jr. ${ }^{2}$ \\ ${ }^{1}$ Bascom Palmer Eye Institute, Miller School of Medicine, University of Miami, 311 9th Street North, No. 100, Naples, \\ FL 34102, USA \\ ${ }^{2}$ Vanderbilt Eye Institute, Vanderbilt University Medical Center, 2311 Pierce Avenue, Nashville, TN 37232, USA \\ Correspondence should be addressed to Stephen G. Schwartz, sschwartz2@med.miami.edu
}

Received 18 June 2011; Accepted 11 August 2011

Academic Editor: Kenji Yamashiro

Copyright ( $) 2011$ S. G. Schwartz and M. A. Brantley Jr. This is an open access article distributed under the Creative Commons Attribution License, which permits unrestricted use, distribution, and reproduction in any medium, provided the original work is properly cited.

\begin{abstract}
Pharmacogenetics seeks to explain interpatient variability in response to medications by investigating genotype-phenotype correlations. There is a small but growing body of data regarding the pharmacogenetics of both nonexudative and exudative agerelated macular degeneration. Most reported data concern polymorphisms in the complement factor H and age-related maculopathy susceptibility 2 genes. At this time, the data are not consistent and no definite conclusions may be drawn. As clinical trials data continue to accumulate, these relationships may become more apparent.
\end{abstract}

\section{Introduction}

Pharmacogenetics, an evolving research discipline within ophthalmology, investigates genotype-phenotype correlations in an attempt to explain interpatient variability in response to medications. While the earliest ophthalmic pharmacogenetic reports involved the treatment of open-angle glaucoma $[1,2]$, there is now a growing body of data concerning various treatments for age-related macular degeneration (AMD).

The combination of antioxidants and zinc studied by the Age-Related Eye Disease Study (AREDS) was reported to reduce disease progression and visual loss in certain patients with nonexudative AMD [3]. These supplements remain the only clinically proven treatment for nonexudative AMD. A variety of treatments have demonstrated efficacy in the treatment of choroidal neovascularization (CNV) secondary to exudative AMD, including photodynamic therapy (PDT) with verteporfin (Visudyne, Novartis, Basel, Switzerland) and the antivascular endothelial growth factor (VEGF) agents. Currently, there are three anti-VEGF agents in clinical use in the US: pegaptanib (Macugen, Eyetech, Palm Beach Gardens, Fla) [4], ranibizumab (Lucentis, Genentech, South San Francisco, Calif) [5, 6], and bevacizumab (Avastin, Genentech, South San Francisco, Calif) [7]. Despite the overall efficacy of these treatments, there remains a persistent and unexplained variability in treatment response with certain patients, especially those treated with anti-VEGF agents [8]. Intravitreal triamcinolone acetonide has been reported to show some efficacy as an adjunctive therapy in some patients with CNV, especially when combined with PDT [9] or bevacizumab [10]. Unfortunately, elevation of intraocular pressure is an important adverse event associated with this treatment [11].

Pharmacogenetics may help to explain some of this variability in treatment efficacy and toxicity.

\section{Studied Genotypes}

The complement system appears to play an important role in the pathogenesis of AMD [12]. Recent studies demonstrated that a single nucleotide polymorphism (SNP) in the complement factor $\mathrm{H}(\mathrm{CFH})$ gene is strongly linked with AMD [13-16]. As a primary regulator of the complement cascade, $\mathrm{CFH}$ plays an important role in innate immunity and inflammatory response. In these studies, individuals with one risk allele for this SNP (genotype TC) had a significantly increased risk of AMD (odds ratios (ORs) ranging from 2.5 to 4.6), and two risk alleles (genotype CC) conferred a correspondingly higher risk (ORs ranging from 3.3 to 7.4). Multiple reports have confirmed this 
association in different populations [17-21]. The influence of the complement pathway on AMD was further validated when polymorphisms in the complement factor B/C2 $(C F B)$, $\mathrm{C} 3$, factor I (FI), and CFH-related proteins 1 and 3 were also shown to influence AMD susceptibility [22-27].

A second locus, encompassing the ARMS2 (age-related maculopathy susceptibility 2, also called LOC387715) and HTRA1 (HtrA serine peptidase 1) genes on chromosome 10q26, has also been consistently associated with AMD [2831]. It has proven difficult to determine whether variants in ARMS2 or HTRA1 are responsible for the association with AMD because they are in strong linkage disequilibrium and their effects are statistically indistinguishable. The function of the ARMS2 protein is unknown. There is some evidence that the HTRA1 polymorphism is functional and influences gene expression, but these data have been inconsistent, and this continues to be debated [32-38].

Polymorphisms in numerous other genes may exert smaller effects on AMD susceptibility. Two recent genomewide association studies (GWAS) showed that the hepatic lipase $(L I P C)$ and tissue inhibitor of metalloprotease 3 (TIMP3) genes may influence AMD risk [39, 40].

Apolipoprotein E levels, encoded by $A P O E$, also have been associated with AMD [41]. Although VEGF (also known as VEGFA) has not been reported to be a major AMD susceptibility locus, polymorphisms within this gene have been associated with exudative AMD in some studies $[42,43]$. Similarly, VEGF receptor 2, encoded by kinase insert domain receptor $(K D R)$, may play a role in the development of CNV [44]. Plasma levels of C-reactive protein, encoded by $C$-reactive protein $(C R P)$, have been associated with AMD $[45,46]$. Low-density lipoprotein receptor-related protein 5 (LRP5) and frizzled homolog 4 (FZD4) have been associated with retinal vascularization but not specifically with AMD [47]. Pigment epithelium-derived factor (PEDF) polymorphisms have also been studied in AMD patients [48].

The glucocorticoid receptor gene $(G R)$ has six wellstudied polymorphisms: ER22/23EK [49], N363S [50], BclI [51], N766N, a substitution within intron 3, and a substitution within intron 4 [52]. None of these SNPs is reported to represent an AMD susceptibility locus, but several have been associated with altered sensitivity to glucocorticoids in nonophthalmic studies.

\section{Pharmacogenomics of AREDS Vitamins}

A subset of patients studied in the AREDS trials was evaluated for a pharmacogenetic response with respect to polymorphisms in CFH Y402H and ARMS2/LOC387715 A69S (Table 1). A total of 264 of 876 AREDS category 3 and 4 patients $(30.1 \%)$ progressed to advanced AMD over five years. In these patients, the CFH TT genotype was associated with a significantly more favorable treatment response than was the CFH CC genotype. Specifically, AREDS supplementation was associated with a greater reduction in AMD progression $(68 \%)$ in those with the low-risk TT genotype compared with those with the high-risk CC genotype (11\%) [53]. No significant associations with AMD progression were seen for the ARMS2 A69S variant.
TABLE 1: Pharmacogenetics of AREDS vitamins and intravitreal triamcinolone acetonide.

\begin{tabular}{|c|c|c|}
\hline Treatment & Genes & Result \\
\hline AREDS vitamins & $\begin{array}{l}C F H \text { and } \\
\text { ARMS2 }\end{array}$ & $\begin{array}{l}C F H \text { TT associated with greater } \\
\text { reduction in disease progression; } \\
\text { no effect with } A R M S 2 \text { [53] }\end{array}$ \\
\hline IVTA & Multiple & $\begin{array}{l}\text { No association between IOP } \\
\text { elevation and any gene [54] }\end{array}$ \\
\hline
\end{tabular}

AREDS: Age-Related Eye Disease Study; IOP: intraocular pressure; IVTA: intravitreal triamcinolone acetonide.

\section{Pharmacogenetics of PDT}

Several studies have investigated the relationship between genetic variants and response to PDT (Table 2). The majority of these have focused on the AMD-associated variants $\mathrm{CFH}$ Y402H and ARMS2 A69S. Other genes, such as those related to the angiogenesis and coagulation pathways, have also been examined.

The first AMD pharmacogenetic study involved a small series of 27 English patients treated with PDT and genotyped for $C F H$ Y402H. Following treatment, patients with $C F H$ CC lost a median of 12 letters of visual acuity (VA) $(P=0.038$ compared to CFH TT), while patients with CFH CT lost a median of 3.5 letters $(P=0.087)$. This study suggested that patients with two $C F H \mathrm{Y} 402 \mathrm{H}$ risk alleles fared worse with PDT than those with one risk allele. However, the analysis was limited by having only two treated patients with the $C F H$ Y402H TT genotype, making it difficult to draw conclusions [55].

A subsequent study examined a series of 69 US patients treated with PDT and genotyped for CFH Y402H [56]. Adjusting for lesion type, lesion size, and pretreatment VA, the mean VA after PDT in this study was significantly worse for patients with the CFH TT genotype than for the CFH TC or $C F H$ CC genotypes. This difference was significant for all patients $(P=0.05)$, as well as for the subgroup of patients with predominantly classic CNV $(P=0.04)$, but not for patients with occult CNV $(P=0.22)$. This suggests that the association between PDT outcome and CFH genotype in this study was driven by those patients with predominantly classic lesions. The authors examined ARMS2 A69S genotypes as well and found no statistically significant differences among treatment outcomes with respect to genotype.

Other studies investigating PDT and CFH Y402H have shown no associations between this polymorphism and treatment outcome. A series of 88 Finnish patients treated with PDT was evaluated for an association with the CFH Y402H SNP [57]. This study used a binary responder/nonresponder outcome classification. Patients were considered to be PDT responders if the treating physician deemed the neovascular lesion to be dry without leakage on fluorescein angiography at least 12 weeks after the last treatment. PDT nonresponders were patients whose lesions did not meet this criterion. The investigators found no statistically significant differences among $\mathrm{CFH} \mathrm{Y402H}$ genotypes with respect to PDT response or the median number of treatments required. 
TABLE 2: Pharmacogenetics of photodynamic therapy.

\begin{tabular}{|c|c|c|}
\hline Treatment & Genes & Result \\
\hline PDT & $\mathrm{CFH}$ & CFH CC associated with worse visual outcomes [55] \\
\hline PDT & CFH and $A R M S 2$ & $\begin{array}{l}\text { CFH TT associated with worse visual outcomes, especially in predominantly } \\
\text { classic CNV; no association with ARMS2 [56] }\end{array}$ \\
\hline PDT & $\mathrm{CFH}$ & No association with PDT responders versus nonresponders [57] \\
\hline PDT & $\mathrm{CFH}$ & No association with visual acuity outcomes [58] \\
\hline PDT & ARMS2 and HTRA1 & $\begin{array}{l}\text { No association with visual acuity outcomes or number of PDT sessions with } \\
\text { either gene [59] }\end{array}$ \\
\hline PDT & $C F H$ and $C R P$ & $\begin{array}{l}\text { No effect with } C F H ; 2 \text { of } 9 C R P \text { polymorphisms associated with more } \\
\text { favorable response to treatment }[60]\end{array}$ \\
\hline PDT & $\begin{array}{l}C F H, H T R A 1, V E G F \\
\quad \text { and } P E D F\end{array}$ & $\begin{array}{l}\text { HTRA1 GG associated with more favorable treatment outcomes; combination } \\
\text { of } 2 \mathrm{CFH} \text { genotypes associated with reduced time interval until disease } \\
\text { recurrence; no association with other genes [61] }\end{array}$ \\
\hline PDT & VEGF & 2 polymorphisms associated with response to treatment [62] \\
\hline \multirow{2}{*}{ PDT } & \multirow{2}{*}{ Multiple } & $\begin{array}{l}\text { In classic CNV, prothrombin and MTFHR associated with PDT responders; } \\
\text { factor XIII-A associated with PDT nonresponders; factor V, methionine } \\
\text { synthase; methionine synthase reductase not associated with PDT response } \\
{[63]}\end{array}$ \\
\hline & & $\begin{array}{l}\text { In occult } \mathrm{CNV} \text {, combination of factor } \mathrm{V} \text { and prothrombin associated with } \\
\text { PDT responders; factor XIII-A associated with PDT nonresponders; MTFHR, } \\
\text { methionine synthase; methionine synthase reductase not associated with PDT } \\
\text { response [64] }\end{array}$ \\
\hline
\end{tabular}

CNV: choroidal neovascularization, PDT: photodynamic therapy.

A study including 131 Israeli patients who were treated with PDT and genotyped for the $C F H \mathrm{Y} 402 \mathrm{H}$ polymorphism used posttreatment VA as the outcome measure. In this series, there were no statistically significant differences in treatment outcomes by $\mathrm{CFH} \mathrm{Y} 402 \mathrm{H}$ genotype, with respect to initial VA, post-PDT VA, or number of PDT sessions required [58]. The same group subsequently published a series of 143 patients treated with PDT and reported that genotypes at both ARMS2 A69S and HTRA1 (rs11200638) were not associated with treatment outcomes, in terms of final VA or number of PDT sessions [59].

In a series of 273 Australian patients treated with PDT and genotyped for $\mathrm{CFH} \mathrm{Y} 402 \mathrm{H}$, participants were divided into responders and nonresponders based on posttreatment VA. Positive responders were those patients who at the final visit had either an improved or unchanged VA or those who lost fewer than 3 lines of vision (provided their final VA was better than or equal to 20/200). Negative responders were those with a final VA of worse than 20/200 or those who lost 3 or more lines of VA. In this study, there were no statistically significant differences in treatment outcomes with respect to the $C F H \mathrm{Y} 402 \mathrm{H}$ genotype. Nine polymorphisms in $C R P$ were also investigated in this study, and two of the nine (rs2808635 GG and rs876538 AA) were significantly correlated with more favorable response to PDT $(P=0.048$ and $P=0.048$, resp.) [60].

A series of 110 Japanese patients treated with PDT was screened for multiple polymorphisms in CFH, HTRA1, VEGF, and PEDF. The HTRA1 rs11200638 GG genotype was associated with significantly improved visual acuity outcomes and significantly less risk of recurrent disease following treatment $(P=0.029)$. The combination of two
CFH genotypes (rs1410996 and rs2274700) was associated with a statistically significant reduction in the time interval until disease recurrence following PDT $(P=0.0085)$. In this study, there was no association between PDT response and CFH SNPs rs 1061170 (Y402H) and rs800292, 3 VEGF SNPs (rs699947, rs1570360, and rs2010963), or four PEDF SNPs (rs12150053, rs12948385, rs9913583, and rs1136287) [61].

A series of 86 Finnish patients treated with PDT was examined in the context of three VEGF polymorphisms using a binary responder/nonresponder classification. As in this group's earlier study, patients were considered PDT responders if the lesion was deemed to be dry at least 12 weeks after the last treatment and PDT nonresponders failed to meet this criterion. Two VEGF polymorphisms (rs699947 and rs2146323) showed a statistically significant relationship to treatment, while one (rs3025033) did not. Regarding the rs699947 genotype, the C allele was associated with a significantly higher percentage of nonresponders $(P=$ $0.0003)$. For the rs2146323 genotype, the $C$ allele was again linked to a higher percentage of PDT nonresponders $(P=$ 0.0036) [62].

Ninety patients treated with PDT for classic CNV were screened for polymorphisms in various genes affecting coagulation, including factor V G1691A, prothrombin G20210A, factor XIII-A G185T, MTHFR C677T, methionine synthase A2756G, and methionine synthase reductase A66G. Patients were classified using a binary responders/nonresponders classification. Responders were significantly associated with the prothrombin G20210A and MTHFR 677T polymorphisms. Nonresponders were significantly associated with the factor XIII-A 185T polymorphism [63]. The same group subsequently reported 84 patients treated with PDT for 
TABLE 3: Pharmacogenetics of antivascular endothelial growth factor therapy.

\begin{tabular}{|c|c|c|}
\hline Treatment & Genes & Result \\
\hline Bevacizumab & $C F H$ and $A R M S 2$ & $\begin{array}{l}\text { CFH CC associated with worse visual outcomes; no association with ARMS2 } \\
{[65]}\end{array}$ \\
\hline Bevacizumab & $\mathrm{CFH}$ & CFH CC associated with worse visual outcomes [66] \\
\hline Ranibizumab & $\mathrm{CFH}$ & CFH CC associated with more injections performed [67] \\
\hline Ranibizumab & CFH and ARMS2 & $\begin{array}{l}\text { ARMS2 TT associated with worse visual outcomes; CFH CC associated with } \\
\text { relatively worse visual outcomes }[68]\end{array}$ \\
\hline Ranibizumab & Multiple & $\begin{array}{l}C F H \text { CC associated with poor treatment response; combination heterozygotes } \\
\text { at } C F H \text { and FZD4 associated with more favorable outcomes; no association } \\
\text { with } C F B, H T R A 1, A R M S 2, V E G F A, K D R \text {, and LRP5 [69] }\end{array}$ \\
\hline Ranibizumab & $\begin{array}{l}\text { CFH, HTRA1, } \\
\text { and VEGF }\end{array}$ & $\begin{array}{l}\text { CFH TC associated with better visual outcomes; no association with number } \\
\text { of injections with any gene [70] }\end{array}$ \\
\hline $\begin{array}{l}\text { Bevacizumab and/or } \\
\text { ranibizumab }\end{array}$ & $A P O E$ & $A P O E \varepsilon 4$ associated with better treatment outcomes [71] \\
\hline
\end{tabular}

occult CNV that were screened for the same six coagulation factor polymorphisms. In this study, nonresponders were significantly associated with the factor XIII-A G185T mutation, and responders were significantly associated with the combination of factor $\mathrm{V} 1691 \mathrm{~A}$ and prothrombin 20210A [64]. Of note, the MTHFR 677T polymorphism that correlated with improved outcomes in patients with classic $\mathrm{CNV}$ did not correlate with improved outcomes in patients with occult CNV [72].

\section{Pharmacogenetics of Anti-VEGF Agents}

A recent group of studies has reported relationships between genetic variation and response to treatment for exudative AMD with anti-VEGF agents (Table 3 ). At this time, all of these reports involve bevacizumab, ranibizumab, or both.

The first study to investigate the association between genetic variants and anti-VEGF treatment for AMD was a retrospective series of 86 US patients treated with bevacizumab monotherapy. Patients were treated every six weeks until the CNV was no longer active and genotyped for the CFH Y402H and ARMS2 A69S polymorphisms. The authors reported the $C F H \mathrm{Y} 402 \mathrm{H}$ genotype to be significantly correlated with treatment response. Patients with the $\mathrm{CFH}$ TT genotype experienced an average VA improvement from 20/248 to 20/166; patients with the CFH TC genotype experienced an average VA improvement from 20/206 to 20/170; patients with the CFH CC genotype experienced an average VA decline from $20 / 206$ to $20 / 341(P=0.016)$. A total of $53.7 \%$ of patients with $C F H$ TT and TC genotypes gained VA with treatment, while only $10.5 \%$ of patients with the $C F H$ CC genotype gained VA with treatment $(P=0.004)$. In this study, there were no statistically significant differences in treatment outcomes associated with the ARMS2/LOC387715 genotype [65].

More recently, similar outcomes were reported by an Austrian group, which presented a prospective series of 197 patients treated with bevacizumab monotherapy. In this study, patients were also treated at six week intervals until inactivity of the lesion. Among patients studied, $41 \%$ of patients with the CFH CC genotype lost 3 or more lines of distance VA, as compared to $28 \%$ of patients with the $C F H$ TT genotype and $26 \%$ of patients with the CFH TC genotype $(P=0.04)[66]$.

Four studies have investigated the pharmacogenetics of ranibizumab monotherapy for AMD. In a retrospective study of 156 US patients treated pro re nata with ranibizumab, the CFH Y $402 \mathrm{H}$ polymorphism correlated with the number of ranibizumab injections performed. Over a 9-month period, patients with the CFH TT genotype required a mean of 3.3 injections; patients with the $C F H$ TC genotype required a mean of 3.8 injections; patients with the CFH CC genotype required a mean of 3.9 injections. A recurrent event analysis demonstrated that patients with the $\mathrm{CFH}$ CC genotype were significantly more likely to require reinjections at a follow-up visit than patients with the CFH TT genotype (OR 1.37, 95\% CI 1.01 to 1.87 ) [67].

A prospective series of 90 Polish patients treated with ranibizumab monotherapy was studied with respect to $\mathrm{CFH}$ Y402H and ARMS2 A69S. All patients experienced statistically significant improvements in VA except patients with the ARMS2 TT genotype (two risk alleles). In addition, the $C F H$ CC genotype was associated with a less significant visual acuity improvement than were the other $\mathrm{CFH}$ genotypes [68].

In an analysis of 243 eyes treated with ranibizumab monotherapy and screened for genotypes at CFH, CFB, HTRA1, ARMS2, VEGFA, KDR, LRP5, and FZD4, there was a statistically significant difference in treatment response with respect to $\mathrm{CFH} \mathrm{Y} 402 \mathrm{H}$. In this study, two responder groups were evaluated: poor responders ( $\leq 25$ th percentile) and good responders ( $\geq 75$ th percentile). The authors reported that $38 \%$ of poor responders were associated with $C F H$ CC, while only $15 \%$ of good responders were associated with $C F H$ CC. Individual polymorphisms in the other genes were not significantly associated with treatment outcomes, but patients who were heterozygous at both $C F H$ and FZD4 had significantly more favorable results; this genotype combination was identified in $36 \%$ of good responders versus $13 \%$ of poor responders [69].

A more recent series of 104 patients treated with ranibizumab monotherapy was screened for genotypes at $\mathrm{CFH}$, 
HTRA1, and VEGF. There were no significant relationships between any genotype and the number of reinjections within the first 6 months. There were nonsignificant trends towards better visual acuity outcomes with certain genotypes in all 3 loci studied. The percentage of patients with a posttreatment increase in VA greater 5 letters was significantly greater among patients with the $C F H$ TC genotype than those with the $C F H$ TT genotype $(P=0.04)$, but there was no difference between the CFH CC and CFH TT genotypes [70].

Finally, a series of 172 patients treated with ranibizumab, bevacizumab, or a combination of the two agents was studied for polymorphisms in APOE. The primary endpoint was two-line improvement in visual acuity. The APOE $\varepsilon 4$ allele was associated with significantly improved treatment outcomes, as compared with the APOE $\varepsilon 2$ allele at 3-month followup $(P=0.02)$, but not at 12 months $(P=0.06)$ [71].

\section{Pharmacogenetics of Corticosteroids}

A series of 52 patients treated with IVTA for a variety of indications, including AMD, was evaluated for a relationship between IOP elevation and 6 polymorphisms in $G R$ (ER22/23EK, N363S, BclI, N766N, and polymorphisms with introns 3 and 4) (Table 1). There were no statistically significant associations between any individual polymorphism, or by haplotype analysis, with IOP elevation following treatment with IVTA [54].

\section{Summary}

Several pilot pharmacogenetic studies have reported some evidence of genotype-phenotype interactions with respect to treatment outcomes using AREDS vitamins, PDT, ranibizumab, and bevacizumab. At this point, the data are conflicting and no definite conclusions may be drawn. The results may be inconsistent because of underlying differences in baseline genetic characteristics, differences in underlying $\mathrm{CNV}$ lesion characteristics (classic versus occult, chronicity, etc.), differences in study endpoints (visual acuity, anatomic response, number of retreatments required, etc.) statistical analysis (use of continuous outcome versus dichotomizing these variables), or other factors.

At this time, pharmacogenetics remains a research tool rather than an option for daily clinical use. Nevertheless, there appears to be a relationship between CFH, ARMS2, and perhaps other genes with respect to treatment outcomes. As we continue to collect data from clinical trials, these relationships may become more apparent.

\section{Acknowledgments}

This work was partially supported by the Jahnigen Career Development Award from the American Geriatrics Society and the Carl M. and Mildred A. Reeves Foundation (MAB), NIH Center Grants P30-EY014801 and P30-EY08126, and unrestricted grants to the University of Miami and Vanderbilt University from Research to Prevent Blindness, New York, NY, USA. S. G. Schwartz is a consultant for Alimera
Sciences and Bausch + Lomb, and is coholder of a patent licensed to IC Labs entitled "Molecular targets for modulating intraocular pressure and differentiation of steroid responders versus non-responders."

\section{References}

[1] S. G. Schwartz, B. J. Puckett, R. C. Allen, I. G. Castillo, and C. T. Leffler, " $\beta 1$-Adrenergic receptor polymorphisms and clinical efficacy of betaxolol hydrochloride in normal volunteers," Ophthalmology, vol. 112, no. 12, pp. 2131-2136, 2005.

[2] M. Sakurai, T. Higashide, M. Takahashi, and K. Sugiyama, "Association between genetic polymorphisms of the prostaglandin F $\alpha$ receptor gene and response to latanoprost," Ophthalmology, vol. 114, no. 6, pp. 1039-1045, 2007.

[3] Age-Related Eye Disease Study Research Group, "A randomized, placebo-controlled, clinical trial of high-dose supplementation with vitamins $c$ and e and beta carotene for agerelated cataract and vision loss: AREDS report no. 8," Archives of Ophthalmology, vol. 119, no. 10, pp. 1439-1452, 2001.

[4] E. S. Gragoudas, A. P. Adamis, E. T. Cunningham Jr. et al., "Pegaptanib for neovascular age-related macular degeneration," New England Journal of Medicine, vol. 351, no. 27, pp. 2805-2816, 2004.

[5] P. J. Rosenfeld, D. M. Brown, J. S. Heier et al., "Ranibizumab for neovascular age-related macular degeneration," New England Journal of Medicine, vol. 355, no. 14, pp. 1419-1431, 2006.

[6] D. M. Brown, P. K. Kaiser, M. Michels et al., "Ranibizumab versus verteporfin for neovascular age-related macular degeneration," New England Journal of Medicine, vol. 355, no. 14, pp. 1432-1444, 2006.

[7] P. J. Rosenfeld, A. A. Moshfeghi, and C. A. Puliafito, "Optical coherence tomography findings after an intravitreal injection of bevacizumab (Avastin) for neovascular age-related macular degeneration," Ophthalmic Surgery Lasers and Imaging, vol. 36, no. 4, pp. 331-335, 2005.

[8] M. Menghini, M. M. Kurz-Levin, C. Amstutz et al., "Response to ranibizumab therapy in neovascular AMD- An evaluation of good and bad responders," Klinische Monatsblatter fur Augenheilkunde, vol. 227, no. 4, pp. 244-248, 2010.

[9] A. Chan, M. S. Blumenkranz, K. H. Wu et al., "Photodynamic therapy with and without adjunctive intravitreal triamcinolone acetonide: a retrospective comparative study," Ophthalmic Surgery Lasers and Imaging, vol. 40, no. 6, pp. 561569, 2009.

[10] H. Ahmadieh, R. Taei, M. Riazi-Esfahani et al., "Intravitreal bevacizumab versus combined intravitreal bevacizumab and triamcinolone for neovascular age-related macular degeneration: six-month results of a randomized clinical trial," Retina. In press.

[11] L. M. Smithen, M. D. Ober, L. Maranan, and R. F. Spaide, "Intravitreal triamcinolone acetonide and intraocular pressure," American Journal of Ophthalmology, vol. 138, no. 5, pp. 740-743, 2004.

[12] P. C. Issa, N. V. Chong, and H. P. N. Scholl, "The significance of the complement system for the pathogenesis of age-related macular degeneration: current evidence and translation into clinical application," Graefe's Archive for Clinical and Experimental Ophthalmology, vol. 249, pp. 163-1174, 2011.

[13] A. O. Edwards, R. Ritter III, K. J. Abel et al., "Complement factor H polymorphism and age-related macular degeneration," Science, vol. 308, no. 5720, pp. 421-424, 2005. 
[14] J. L. Haines, M. A. Hauser, S. Schmidt et al., "Complement factor $\mathrm{H}$ variant increases the risk of age-related macular degeneration," Science, vol. 308, no. 5720, pp. 419-421, 2005.

[15] R. J. Klein, C. Zeiss, E. Y. Chew et al., "Complement factor H polymorphism in age-related macular degeneration," Science, vol. 308, no. 5720, pp. 385-389, 2005.

[16] G. S. Hageman, D. H. Anderson, L. V. Johnson et al., "A common haplotype in the complement regulatory gene factor $\mathrm{H}(\mathrm{HF} 1 / \mathrm{CFH})$ predisposes individuals to age-related macular degeneration," Proceedings of the National Academy of Sciences of the United States of America, vol. 102, no. 20, pp. 7227-7232, 2005.

[17] S. Zareparsi, K. E. Branham, M. Li et al., "Strong association of the $\mathrm{Y} 402 \mathrm{H}$ variant in complement factor $\mathrm{H}$ at $1 \mathrm{q} 32$ with susceptibility to age-related macular degeneration," American Journal of Human Genetics, vol. 77, no. 1, pp. 149-153, 2005.

[18] E. H. Souied, N. Leveziel, F. Richard et al., "Y402H complement factor $\mathrm{H}$ polymorphism associated with exudative age-related macular degeneration in the French population," Molecular Vision, vol. 11, pp. 1135-1140, 2005.

[19] F. Simonelli, G. Frisso, F. Testa et al., "Polymorphism p. $402 \mathrm{Y}>\mathrm{H}$ in the complement factor $\mathrm{H}$ protein is a risk factor for age related macular degeneration in an Italian population," British Journal of Ophthalmology, vol. 90, no. 9, pp. 1142-1145, 2006.

[20] D. D. Despriet, C. C. Klaver, J. C. Witteman et al., "Complement factor $\mathrm{H}$ polymorphism, complement activators, and risk of age-related macular degeneration," Journal of the American Medical Association, vol. 296, no. 3, pp. 301-309, 2006.

[21] S. Seitsonen, S. Lemmela, J. Holopainen et al., "Analysis of variants in the complement factor $\mathrm{H}$, the elongation of very long chain fatty acids-like 4 and the hemicentin 1 genes of age-related macular degeneration in the Finnish population," Molecular Vision, vol. 12, pp. 796-801, 2006.

[22] B. Gold, J. E. Merriam, J. Zernant et al., "Variation in factor B $(B F)$ and complement component $2(C 2)$ genes is associated with age-related macular degeneration," Nature Genetics, vol. 38, no. 4, pp. 458-462, 2006.

[23] J. R. Yates, T. Sepp, B. K. Matharu et al., "Complement C3 variant and the risk of age-related macular degeneration," New England Journal of Medicine, vol. 357, no. 6, pp. 553-561, 2007.

[24] J. A. Fagerness, J. B. Maller, B. M. Neale et al., "Variation near complement factor I is associated with risk of advanced AMD," European Journal of Human Genetics, vol. 17, no. 1, pp. 100104, 2009.

[25] S. Ennis, S. Goverdhan, A. Cree et al., "Fine-scale linkage disequilibrium mapping of age-related macular degeneration in the complement factor $\mathrm{H}$ gene region," British Journal of Ophthalmology, vol. 91, no. 7, pp. 966-970, 2007.

[26] G. S. Hageman, L. S. Hancox, A. J. Taiber et al., "Extended haplotypes in the complement factor $\mathrm{H}(\mathrm{CFH})$ and $\mathrm{CFH}-$ related (CFHR) family of genes protect against age-related macular degeneration: characterization, ethnic distribution and evolutionary implications," Annals of Medicine, vol. 38, no. 8, pp. 592-604, 2006.

[27] A. E. Hughes, N. Orr, H. Esfandiary et al., "A common CFH haplotype, with deletion of CFHR1 and CFHR3, is associated with lower risk of age-related macular degeneration," Nature Genetics, vol. 38, no. 10, pp. 1173-1177, 2006.

[28] J. Jakobsdottir, Y. P. Conley, D. E. Weeks et al., "Susceptibility genes for age-related maculopathy on chromosome 10q26,"
American Journal of Human Genetics, vol. 77, no. 3, pp. 389407, 2005.

[29] A. Rivera, S. A. Fisher, L. G. Fritsche et al., "Hypothetical LOC387715 is a second major susceptibility gene for agerelated macular degeneration, contributing independently of complement factor $\mathrm{H}$ to disease risk," Human Molecular Genetics, vol. 14, no. 21, pp. 3227-3236, 2005.

[30] Z. Yang, N. J. Camp, H. Sun et al., "A variant of the HTRA1 gene increases susceptibility to age-related macular degeneration," Science, vol. 314, no. 5801, pp. 992-993, 2006.

[31] A. Dewan, M. Liu, S. Hartman et al., "HTRA1 promoter polymorphism in wet age-related macular degeneration," Science, vol. 314, no. 5801, pp. 989-992, 2006.

[32] C. C. Chan, D. Shen, M. Zhou et al., "Human HtrA1 in the archived eyes with age-related macular degeneration," Transactions of the American Ophthalmological Society, vol. 105, pp. 92-97, 2007.

[33] A. Kanda, W. Chen, M. Othman et al., "A variant of mitochondrial protein LOC387715/ARMS2, not HTRA1, is strongly associated with age-related macular degeneration," Proceedings of the National Academy of Sciences of the United States of America, vol. 104, no. 41, pp. 16227-16232, 2007.

[34] J. Tuo, R. J. Ross, G. F. Reed et al., "The HtrA1 promoter polymorphism, smoking, and age-related macular degeneration in multiple case-control samples," Ophthalmology, vol. 115, no. 11, pp. 1891-1898, 2008.

[35] A. Kanda, D. Stambolian, W. Chen et al., "Age-related macular degeneration-associated variants at chromosome 10q26 do not significantly alter ARMS2 and HTRA1 transcript levels in the human retina," Molecular Vision, vol. 16, pp. 1317-1323, 2010.

[36] G. Wang, W. K. Scott, J. L. Haines, and M. A. PericakVance, "Genotype at polymorphism rs11200638 and HTRA1 expression level," Archives of Ophthalmology, vol. 128, no. 11, pp. 1491-1493, 2010.

[37] Z. Yang, Z. Tong, Y. Chen et al., "Genetic and functional dissection of HTRA1 and LOC387715 in age-related macular degeneration," PLoS Genetics, vol. 6, no. 2, Article ID e1000836, 2010.

[38] U. Friedrich, C. A. Myers, L. G. Fritsche et al., "Risk-and nonrisk-associated variants at the 10q26 AMD locus influence ARMS2 mRNA expression but exclude pathogenic effects due to protein deficiency," Human Molecular Genetics, vol. 20, no. 7, pp. 1387-1399, 2011.

[39] B. M. Neale, J. Fagerness, R. Reynolds et al., "Genome-wide association study of advanced age-related macular degeneration identifies a role of the hepatic lipase gene (LIPC)," Proceedings of the National Academy of Sciences of the United States of America, vol. 107, no. 16, pp. 7395-7400, 2010.

[40] W. Chen, D. Stambolian, A. O. Edwards et al., "Genetic variants near TIMP3 and high-density lipoprotein-associated loci influence susceptibility to age-related macular degeneration," Proceedings of the National Academy of Sciences of the United States of America, vol. 107, no. 16, pp. 7401-7406, 2010.

[41] P. N. Baird, E. Guida, D. T. Chu et al., "The $\varepsilon 2$ and $\varepsilon 4$ alleles of the apolipoprotein gene are associated with agerelated macular degeneration," Investigative Ophthalmology and Visual Science, vol. 45, no. 5, pp. 1311-1315, 2004.

[42] A. J. Churchill, J. G. Carter, H. C. Lovell et al., "VEGF polymorphisms are associated with neovascular age-related macular degeneration," Human Molecular Genetics, vol. 15, no. 19, pp. 2955-2961, 2006. 
[43] J. L. Haines, N. Schnetz-Boutaud, S. Schmidt et al., "Functional candidate genes in age-related macular degeneration: significant association with VEGF, VLDLR, and LRP6," Investigative Ophthalmology and Visual Science, vol. 47, no. 1, pp. 329-335, 2006.

[44] N. Ferrara, "Vascular endothelial growth factor: basic science and clinical progress," Endocrine Reviews, vol. 25, no. 4, pp. 581-611, 2004.

[45] J. M. Seddon, G. Gensler, R. C. Milton et al., "Association between $\mathrm{C}$-reactive protein and age-related macular degeneration," Journal of the American Medical Association, vol. 291, no. 6, pp. 704-710, 2004.

[46] S. S. Boekhoorn, J. R. Vingerling, J. C. M. Witteman et al., "Creactive protein level and risk of aging macula disorder: the Rotterdam study," Archives of Ophthalmology, vol. 125, no. 10, pp. 1396-1401, 2007.

[47] X. Ye, Y. Wang, H. Cahill et al., "Norrin, Frizzled-4, and Lrp5 signaling in endothelial cells controls a genetic program for retinal vascularization," Cell, vol. 139, no. 2, pp. 285-298, 2009.

[48] Y. Qu, X. Zhang, H. Dai et al., "Pigment epithelium-derived factor gene polymorphisms in exudative age-related degeneration in a Chinese cohort," Current Eye Research, vol. 36, no. 1, pp. 60-65, 2011.

[49] E. F. van Rossum, J. W. Koper, N. A. Huizenga et al., "A polymorphism in the glucocorticoid receptor gene, which decreases sensitivity to glucocorticoids in vivo, is associated with low insulin and cholesterol levels," Diabetes, vol. 51, no. 10, pp. 3128-3134, 2002.

[50] N. A. Huizenga, J. W. Koper, P. de Lange et al., "A polymorphism in the glucocorticoid receptor gene may be associated with an increased sensitivity to glucocorticoids in vivo," Journal of Clinical Endocrinology and Metabolism, vol. 83, no. 1, pp. 144-151, 1998.

[51] E. F. van Rossum, J. W. Koper, A. W. van den Beld et al., "Identification of the Bc/I polymorphism in the glucocorticoid receptor gene: association with sensitivity to glucocorticoids in vivo and body mass index," Clinical Endocrinology, vol. 59, no. 5, pp. 585-592, 2003.

[52] J. W. Koper, R. P. Stolk, P. de Lange et al., "Lack of association between five polymorphisms in the human glucocorticoid receptor gene and glucocorticoid resistance," Human Genetics, vol. 99, no. 5, pp. 663-668, 1997.

[53] M. L. Klein, P. J. Francis, B. Rosner et al., "CFH and LOC387715/ARMS2 genotypes and treatment with antioxidants and zinc for age-related macular degeneration," Ophthalmology, vol. 115, no. 6, pp. 1019-1025, 2008.

[54] S. M. Gerzenstein, M. T. Pletcher, A. C. L. Cervino et al., "Glucocorticoid receptor polymorphisms and intraocular pressure response to intravitreal triamcinolone acetonide," Ophthalmic Genetics, vol. 29, no. 4, pp. 166-170, 2008.

[55] S. V. Goverdhan, S. Hannan, R. B. Newsom et al., "An analysis of the CFH Y402H genotype in AMD patients and controls from the UK, and response to PDT treatment," Eye, vol. 22, no. 6, pp. 849-854, 2008.

[56] M. A. Brantley Jr., S. L. Edelstein, J. M. King et al., "Association of complement factor $\mathrm{H}$ and LOC387715 genotypes with response of exudative age-related macular degeneration to photodynamic therapy," Eye, vol. 23, no. 3, pp. 626-631, 2009.

[57] S. P. Seitsonen, I. E. Jarvela, S. Meri et al., "The effect of complement factor $\mathrm{H} \mathrm{Y} 402 \mathrm{H}$ polymorphism on the outcome of photodynamic therapy in age-related macular degeneration,"
European Journal of Ophthalmology, vol. 17, no. 6, pp. 943949, 2007.

[58] I. Chowers, Y. Cohen, G. Goldenberg-Cohen et al., "Association of complement factor $\mathrm{H} \mathrm{Y} 402 \mathrm{H}$ polymorphism with phenotype of neovascular age related macular degeneration in Israel," Molecular Vision, vol. 14, pp. 1829-1834, 2008.

[59] I. Chowers, T. Meir, M. Lederman et al., "Sequence variants in HTRA1 and LOC387715/ARMS2 and phenotype and response to photodynamic therapy in neovascular age-related macular degeneration in populations from Israel," Molecular Vision, vol. 14, pp. 2263-2271, 2008.

[60] X. Feng, J. Xiao, B. Longville et al., "Complement factor $\mathrm{H}$ $\mathrm{Y} 402 \mathrm{H}$ and C-reactive protein polymorphism and photodynamic therapy response in age-related macular degeneration," Ophthalmology, vol. 116, no. 10, pp. 1908-1912, 2009.

[61] T. Tsuchihashi, K. Mori, K. Horie-Inoue et al., "Complement factor $\mathrm{H}$ and high-temperature requirement A-1 genotypes and treatment response of age-related macular degeneration," Ophthalmology, vol. 118, no. 1, pp. 93-100, 2011.

[62] I. Immonen, S. Seitsonen, P. Tommila et al., "Vascular endothelial growth factor gene variation and the response to photodynamic therapy in age-related macular degeneration," Ophthalmology, vol. 117, no. 1, pp. 103-108, 2010.

[63] F. Parmeggiani, C. Costagliola, D. Gemmati et al., "Predictive role of coagulation-balance gene polymorphisms in the efficacy of photodynamic therapy with verteporfin for classic choroidal neovascularization secondary to age-related macular degeneration," Pharmacogenetics and Genomics, vol. 17, no. 12, pp. 1039-1046, 2007.

[64] F. Parmeggiani, C. Costagliola, D. Gemmati et al., "Coagulation gene predictors of photodynamic therapy for occult choroidal neovascularization in age-related macular degeneration," Investigative Ophthalmology and Visual Science, vol. 49, no. 7, pp. 3100-3106, 2008.

[65] M. A. Brantley Jr., A. M. Fang, J. M. King et al., "Association of complement factor $\mathrm{H}$ and LOC387715 genotypes with response of exudative age-related macular degeneration to intravitreal bevacizumab," Ophthalmology, vol. 114, no. 12, pp. 2168-2173, 2007.

[66] C. Nischler, H. Oberkofler, C. Ortner et al., "Complement factor $\mathrm{H} \mathrm{Y} 402 \mathrm{H}$ gene polymorphism and response to intravitreal bevacizumab in exudative age-related macular degeneration," Acta Ophthalmologica, vol. 89, no. 4, pp. e344-e349, 2011.

[67] A. Y. Lee, A. K. Raya, S. M. Kymes, A. Shiels, and M. A. Brantley Jr., "Pharmacogenetics of complement factor H (Y402H) and treatment of exudative age-related macular degeneration with ranibizumab," British Journal of Ophthalmology, vol. 93, no. 5, pp. 610-613, 2009.

[68] S. J. Teper, A. Nowinska, J. Pilat, A. Palucha, and E. Wylegala, "Involvement of genetic factors in the response to a variabledosing ranibizumab treatment regimen for age-related macular degeneration," Molecular Vision, vol. 16, pp. 2598-2604, 2010.

[69] B. Kloeckener-Gruissem, D. Barthelmes, S. Labs et al., "Genetic association with response to intravitreal ranibizumab in patients with neovascular AMD," Investigative Ophthalmology \& Visual Science, vol. 52, no. 7, pp. 4694-4702, 2011.

[70] M. McKibbin, M. Ali, S. Bansal et al., "CFH, VEGF and HTRA1 promoter genotype may influence the response to intravitreal ranibizumab therapy for neovascular age-related macular degeneration," British Journal of Ophthalmology. In press. 
[71] S. S. Wickremasinghe, J. Xie, J. Lim et al., "Variants in the APOE gene are associated with improved outcome after anti-VEGF treatment for neovascular AMD," Investigative Ophthalmology \& Visual Science, vol. 52, no. 7, pp. 4072-4079, 2011.

[72] F. Parmeggiani, D. Gemmati, C. Costagliola, A. Sebastiani, and C. Incorvaia, "Predictive role of C677T MTHFR polymorphism in variable efficacy of photodynamic therapy for neovascular age-related macular degeneration," Pharmacogenomics, vol. 10, no. 1, pp. 81-95, 2009. 


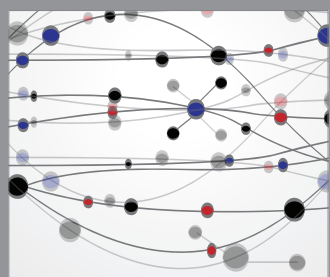

The Scientific World Journal
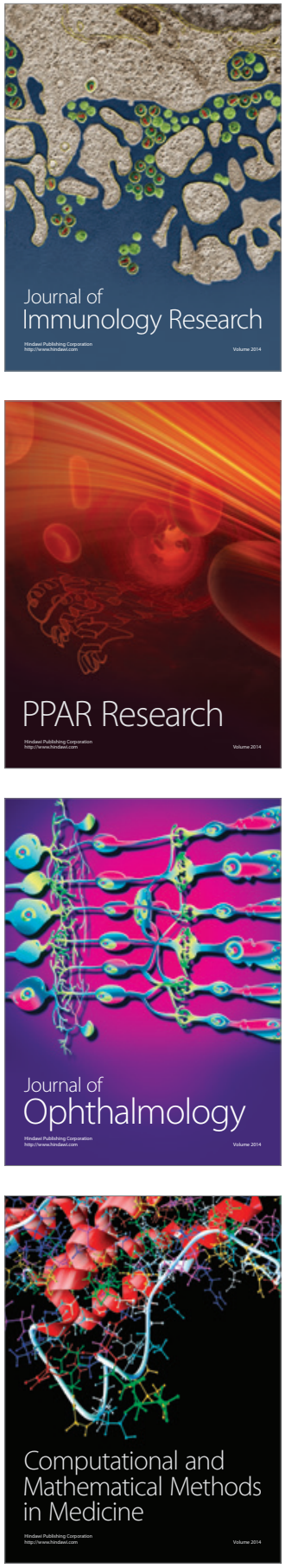

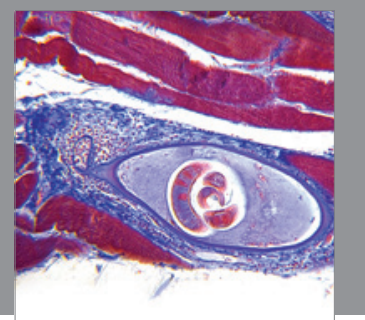

Gastroenterology

Research and Practice
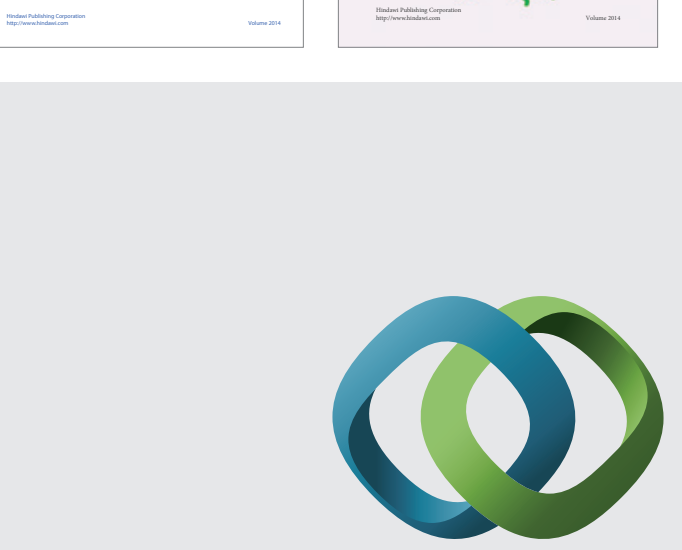

\section{Hindawi}

Submit your manuscripts at

http://www.hindawi.com
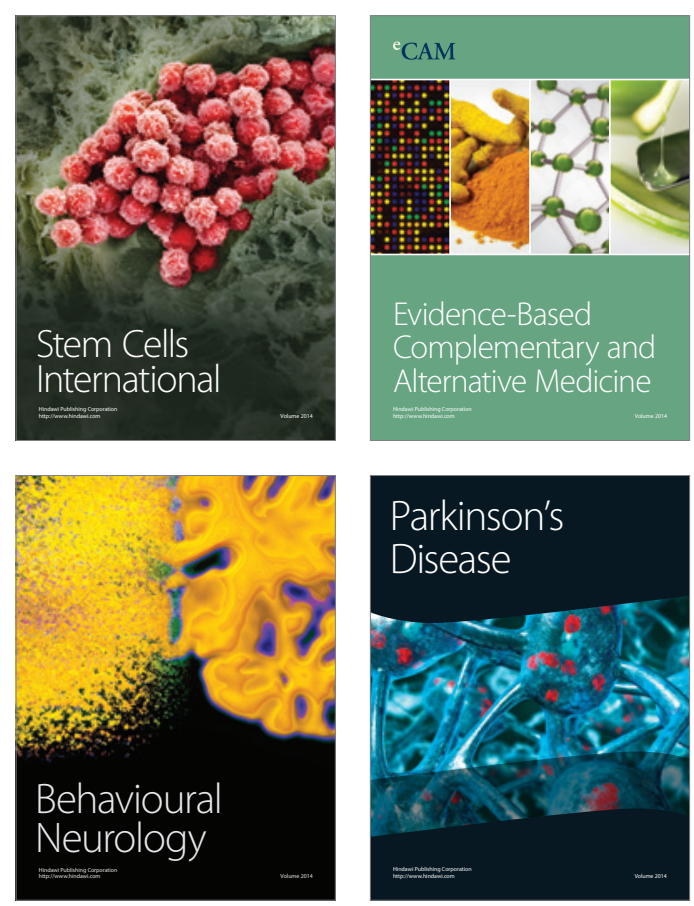

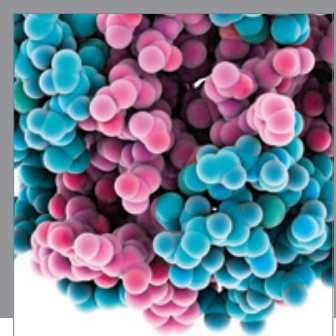

Journal of
Diabetes Research

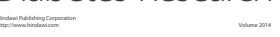

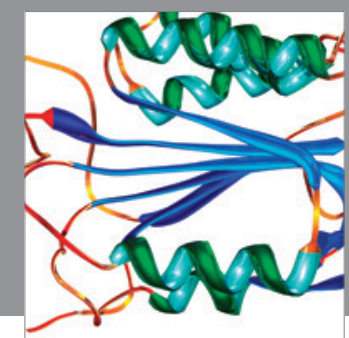

Disease Markers
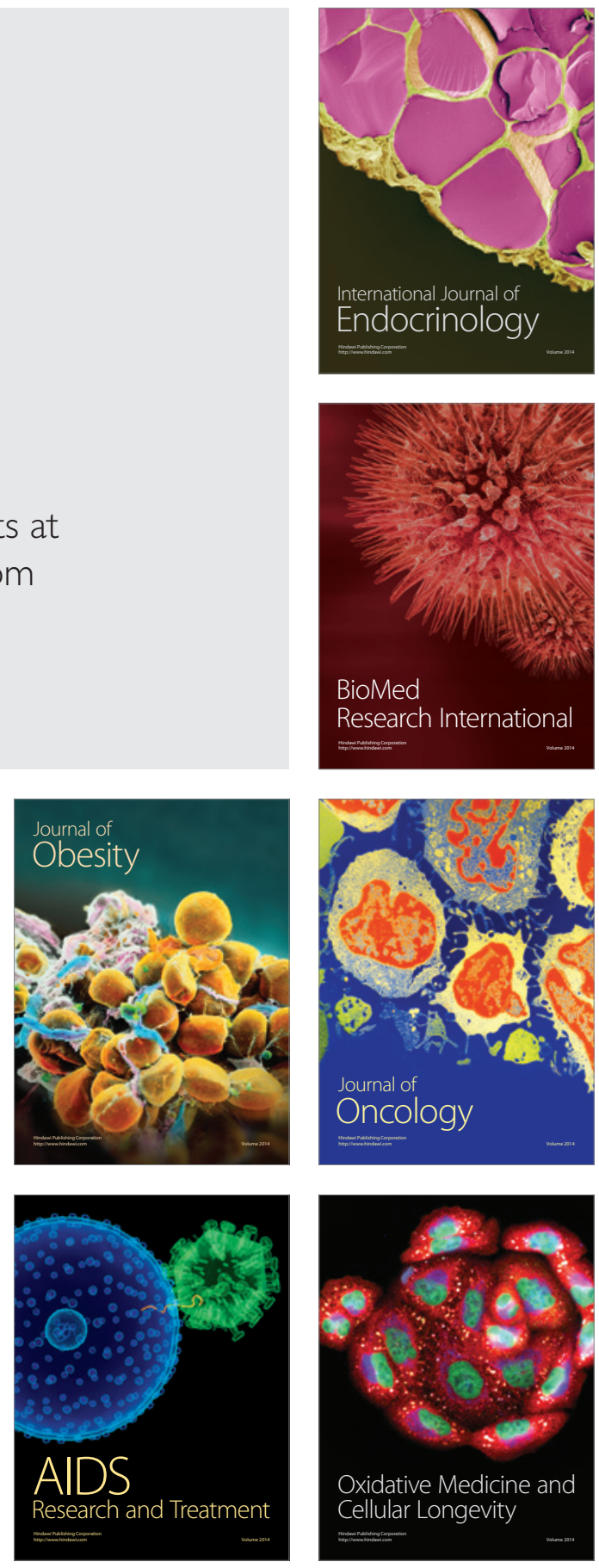